\title{
Evaluation of Strategies for Reducing Taxi-out Emissions at Airports
}

\author{
Indira Deonandan* and Hamsa Balakrishnan ${ }^{\dagger}$ \\ Massachusetts Institute of Technology, Cambridge, MA 02139, USA
}

\begin{abstract}
Aircraft taxiing on the surface contribute significantly to the fuel burn and emissions at airports. This paper is aimed at estimating the baseline fuel burn and emissions from taxi-out processes at airports, evaluating the potential benefits of strategies proposed to reduce them, and assessing the critical implementation barriers that need to be overcome prior to the adoption of these approaches at airports. This study evaluates the effects of two different strategies, namely, single engine taxiing and operational tow-outs, as well as the total potential decrease in taxi times, fuel burn and emissions that may be obtained through various operational improvements at airports. The baseline emission calculation is done for all domestic commercial flights in the US for the year 2007, and a comparative study of the effects of these strategies is performed for the top twenty airports (by number of departures) in the US.
\end{abstract}

\section{Introduction}

Aircraft taxiing on the surface contribute significantly to the fuel burn and emissions at airports. The quantities of fuel burned as well as different pollutants such as Carbon Dioxide, Hydrocarbons, Nitrogen Oxides, Sulfur Oxides and Particulate Matter (PM) are a function of the taxi times of aircraft, in addition to other factors such as the throttle settings, number of engines that are powered, and pilot and airline decisions regarding engine shutdowns during delays. In 2007, aircraft in the Unites States spent more than 63 million minutes taxiing in to their gates, and over 150 million minutes taxiing out from their gates; $;^{9}$ in addition, the number of flights with large taxi-out times (for example, over $40 \mathrm{~min}$ ) has been increasing (Table 1). Similar trends have been noted at major airports in Europe, where it is estimated that aircraft spend 10-30\% of their flight time taxiing, and that a short/medium range A320 expends as much as 5-10\% of its fuel on the ground. ${ }^{5}$

\begin{tabular}{|c|c|c|c|c|c|c|c|}
\hline \multirow{2}{*}{ Year } & \multicolumn{7}{|c|}{ Number of flights with taxi-out time (in min) } \\
\cline { 2 - 8 } & $<\mathbf{2 0}$ & $\mathbf{2 0 - 3 9}$ & $\mathbf{4 0 - 5 9}$ & $\mathbf{6 0 - 8 9}$ & $\mathbf{9 0 - 1 1 9}$ & $\mathbf{1 2 0 - 1 7 9}$ & $\geq \mathbf{1 8 0}$ \\
\hline $\mathbf{2 0 0 6}$ & $6.9 \mathrm{mil}$ & $1.7 \mathrm{mil}$ & 197,167 & 49,116 & 12,540 & 5,884 & 1,198 \\
$\mathbf{2 0 0 7}$ & $6.8 \mathrm{mil}$ & $1.8 \mathrm{mil}$ & 235,197 & 60,587 & 15,071 & 7,171 & 1,565 \\
\hline Change & $-1.5 \%$ & $+6 \%$ & $+19 \%$ & $+23 \%$ & $+20 \%$ & $+22 \%$ & $+31 \%$ \\
\hline
\end{tabular}

Table 1. Taxi-out times in the United States, illustrating the increase in the number of flights with large taxi-out times between 2006 and 2007.

The taxi-out time is defined as the time between the actual pushback and wheels-off. This is the time that the aircraft spends on the airport surface with engines on, and includes the time spent on the taxiway system and in the runway queues. Surface emissions from departures are therefore closely linked to the taxi-out times. At several of the busiest airports, the taxi times are large, and tend to be much greater than

${ }^{*}$ Graduate Student, Department of Aeronautics and Astronautics, Massachusetts Institute of Technology, Cambridge, MA 02139. indira@mit.edu.

$\dagger$ Assistant Professor, Department of Aeronautics and Astronautics, Massachusetts Institute of Technology, Cambridge, MA 02139. hamsa@mit.edu. AIAA Member. 


\begin{tabular}{|c||c|c|c|c|c|c|c|c|c|c|}
\hline Airport & JFK & EWR & LGA & PHL & DTW & BOS & IAH & MSP & ATL & IAD \\
\hline \hline Avg. taxi-out time (in min) & 37.1 & 29.6 & 29.0 & 25.5 & 20.8 & 20.6 & 20.4 & 20.3 & 19.9 & 19.7 \\
\hline
\end{tabular}

Table 2. Top 10 airports with the largest taxi-out times in the United States in $2007 .{ }^{16}$

the unimpeded taxi times for those airports (Figure 1). This suggests that it may be possible to decrease taxi times and surface emissions by addressing the inefficiencies in surface operations. ${ }^{10}$

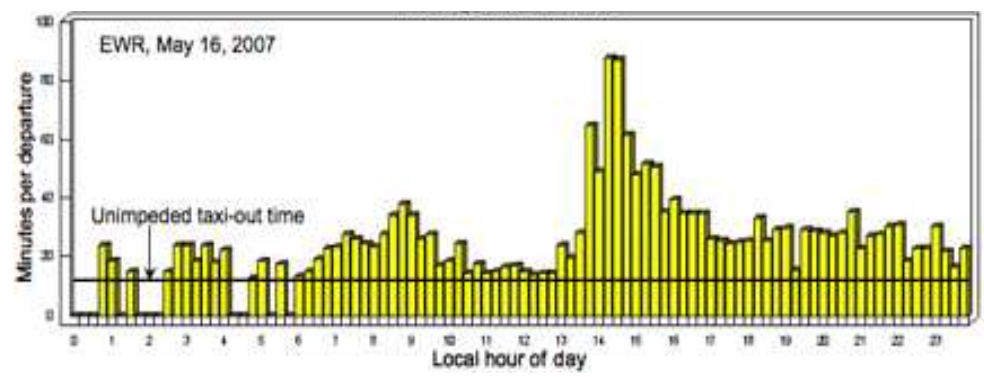

Figure 1. The average departure taxi times at EWR over 15-minute intervals and the unimpeded taxi-out time (according to the ASPM database) from May 16, 2007. We note that large taxi times persisted for a significant portion of the day. ${ }^{9}$

In this paper, we consider two possible approaches to reduce emissions at airports: the first is to use fewer engines to taxi (and thereby reduce the fuel burn and emissions), while the second is to tow aircraft out close to the runway prior to starting their engines. We estimate the potential benefits of each of these approaches and also assess the operational barriers that need to be addressed before they can be adopted. We also estimate the total potential for reduction in taxi times and emissions by computing the optimum unimpeded 'free flow' time (as reported by $\mathrm{ASPM}^{9}$ ).

\section{Baseline emissions}

The baseline aircraft emissions for 2007 were computed using a combination of flight data, airline fleet data and aircraft engine emissions and fuel burn data.

\section{A. Data sources}

The flight schedule data was obtained from the Bureau of Transportation Statistics. ${ }^{16}$ This data is the same as the ASQP data, ${ }^{8}$ and corresponds to "all domestic non-stop flight segments flown by U.S. carriers with at least 1 percent of passenger revenues in the previous year". The BTS records include aircraft tail numbers, scheduled arrival and departure times, origin and destination airports, the On, Off, Out and In (OOOI) times, and thereby the taxi-in and taxi-out durations. The aircraft tail numbers in the BTS database are matched with the data in the JP Airline-Fleets International directory ${ }^{4}$ to determine the aircraft model, number of engines and engine models used for a particular flight segment. In addition, the engine make and model can be matched to their fuel burn and emissions indices (for different pollutants) using the ICAO Engine Emission Databank. ${ }^{15}$ BTS estimates that there were 10.38 million scheduled domestic passenger revenue departures in the US in 2007. Of these, there are 7.46 million records in the BTS/ASQP data. 1.57\% of these records lack tail number information, and $0.62 \%$ of them lack taxi-out time information. Ultimately, 5.57 million flights have all the necessary information (taxi-out times, tail numbers, engine information and emissions indices for $\mathrm{HC}, \mathrm{CO}$ and $\mathrm{NOx}$ ), and 5.76 million flights have all the above information except the HC emissions indices. Therefore, in our assessments, we include about $77 \%$ of all BTS records and $55 \%$ of the estimated 10.38 million flights in 2007.

The amount of missing data also differs (quite significantly) from airport to airport. For example, Table 3 shows the number of departures for which all the associated data (not including the emissions indices for $\mathrm{HC}$ ) is available, the number of departures for which all the associated data (including HC) is available, 
the number of BTS departure records and the number of departures estimated by the Airspace System Performance Metrics $\left(\mathrm{ASPM}^{9}\right.$ ) database for the top 20 originating airports (as measured by the number of ASPM departures). In general, we note that the $\mathrm{HC}$ emissions indices alone are missing for many flights, especially at DFW and ORD. A comparison of the two counts is also shown in Figure 2. We note that the ASPM departure counts are available for 77 airports (known as the "ASPM 77"), while the BTS database contains data from 304 origin airports.

\begin{tabular}{|c|c|c|c|c|c|c|}
\hline \multirow{2}{*}{ Airport } & \multicolumn{2}{|c|}{ No. of departures } & \multicolumn{2}{c|}{ Fuel/CO/NOx data available } & \multicolumn{2}{c|}{ HC data available } \\
\cline { 2 - 7 } & ASPM & BTS & Number & \% of ASPM & Number & \% of ASPM \\
\hline \hline ATL & 490735 & 413851 & 358737 & 73.1 & 355517 & 72.4 \\
ORD & 454568 & 375784 & 313001 & 68.9 & 288407 & 63.4 \\
DFW & 336397 & 297345 & 183836 & 54.6 & 120058 & 35.7 \\
LAX & 315456 & 237597 & 159719 & 50.6 & 155718 & 49.4 \\
DEN & 305534 & 240928 & 210819 & 69.0 & 203035 & 66.5 \\
IAH & 290527 & 200420 & 185925 & 64.0 & 184304 & 63.4 \\
CLT & 241322 & 127108 & 100565 & 41.7 & 99551 & 41.3 \\
PHX & 239472 & 211072 & 192035 & 80.2 & 190137 & 79.4 \\
PHL & 232042 & 104063 & 76478 & 33.0 & 74566 & 32.1 \\
DTW & 228255 & 177478 & 117656 & 51.5 & 116308 & 51.0 \\
LAS & 223126 & 183668 & 160323 & 71.9 & 159011 & 71.3 \\
MSP & 214251 & 155846 & 115589 & 54.0 & 113129 & 52.8 \\
JFK & 209500 & 126366 & 98043 & 46.8 & 97846 & 46.7 \\
EWR & 208583 & 154113 & 137614 & 66.0 & 135341 & 64.9 \\
LGA & 190948 & 122899 & 89597 & 46.9 & 81614 & 42.7 \\
BOS & 182759 & 128320 & 96561 & 52.8 & 94011 & 51.4 \\
SFO & 174249 & 138491 & 100386 & 57.6 & 97910 & 56.2 \\
IAD & 171294 & 91048 & 80113 & 46.8 & 79018 & 46.1 \\
SLC & 171128 & 147808 & 119799 & 70.0 & 118206 & 69.1 \\
MCO & 170533 & 129778 & 107712 & 63.2 & 105295 & 61.7 \\
\hline
\end{tabular}

Table 3. Total number of departures in ASPM and BTS databases for different airports. and the flights for which taxi-time, engine and emissions data are all available.

\section{B. Methodology for estimation of baseline emissions}

For each flight record in the 2007 BTS database, we estimate the emissions contribution of the taxi-out portion of the flight. We focus on three pollutant species, namely, CO, NOx and HC. For each flight, we use the tail number to determine the type and number of engines used, and then the fuel burn and emissions indices from the ICAO engine databank. We assume that aircraft are powered by their Auxiliary Power Units (APUs) during pushback and engine-start (for two minutes), and include the emissions from the APUs. ${ }^{6}$

Using the above information, the taxi-out fuel burn of flight $i$ in $\mathrm{kg}$, denoted $F B_{i}$, is given by

$$
F B_{i}=T_{i} \times N_{i} \times F B I_{i},
$$

where $T_{i}$ is the taxi-out time of flight $i, N_{i}$ is the number of engines on flight $i$ and $F B I_{i}$ is the fuel burn index of each of its engines (in $\mathrm{kg} / \mathrm{sec}$ ).

The emissions from flight $i$ for each pollutant species $j$ (denoted $E_{i j}$, in $\mathrm{kg}$ ) is given by

$$
E_{i j}=T_{i} \times N_{i} \times F B I_{i} \times E I_{i j}
$$

where $E I_{i j}$ is the emissions index for pollutant $j$ from each engine on flight $i$, measured in grams of pollutant per kilogram of fuel consumed. We can sum the above quantities over all departures in the system or in any particular airport in order to obtain the total fuel burn and emissions.

In reality, the taxi-out emissions from an aircraft depend on factors for which data is not available, such as the throttle setting, ambient temperature, number of engines used to taxi, etc. We assume that in the baseline case, all engines are used to taxi-out, and that the throttle setting is $7 \%$ of maximum thrust. In 


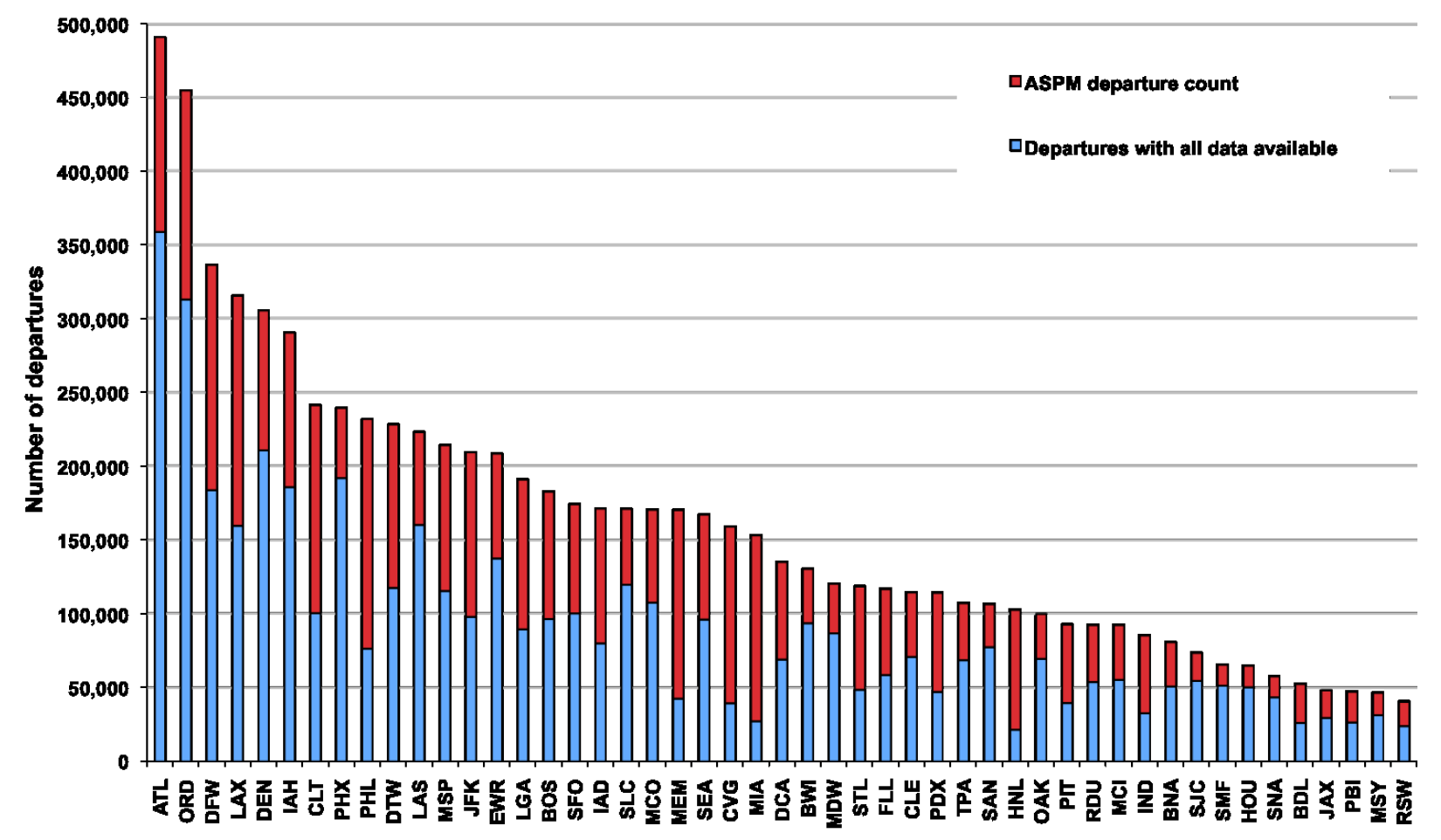

Figure 2. Comparison of departures for which all data is available, and total ASPM departure count for 2007.

reality, throttle settings vary from aircraft to aircraft, and even during the taxi phase of a single flight. Recent experiments have shown that the actual emissions are nonlinear in the low-throttle setting regimes for some pollutants. ${ }^{12-14}$ We are currently working on leveraging these experimental studies to refine our emissions estimates. We also note that some flights do already either adopt single engine taxiing, or stop their engines when a large delay in expected (even away from the gate). In addition, some flights return to their gates when a large delay is assigned to them. These events are not reported in the BTS data, and we ignore their effects in calculating the baseline fuel burn and emissions.

\section{Baseline emissions estimates}

We present two sets of estimates: the first is an estimate of emissions obtained through the aggregation of estimates from Equations (1-2) for all flights for which data are available; the second is an estimate obtained by scaling the results from the previous step proportionately to the total number of flights in the ASPM records. In Figure 3 and the discussion below, "raw" or "unscaled" refers to the contribution of flights for which all the data is available, while "scaled" implies that these values have been scaled to the ASPM departure count for airport $k$ using the formula

$$
F B_{k}^{\text {scaled }}=\frac{F B_{k}^{\text {unscaled }} \times(\text { ASPM departure count of } k)}{\text { Number of departures from } k \text { with data available }} .
$$

Table $\mathrm{C}$ shows the scaled and unscaled fuel burn and emissions for the top 20 airports (as measured by the ASPM departure count) along with the unscaled and ASPM departure counts.

We also consider potential metrics to compare the relative fuel burn and emissions performance of different airports. One possible approach is to normalize the fuel burn at an airport by the maximum fuel burn among all airports (i.e., the fuel burn of ATL) and to compare this value with the departure count at the same airport normalized using the departure count of ATL. This would allow us to draw conclusions of the form "Airport $i$ consumes a fraction $x$ of the fuel consumption at ATL, but faces (only) a fraction $y$ of the ATL 


\begin{tabular}{|c|c|c|c|c|c|c|c|c|c|c|}
\hline & \multicolumn{2}{|c|}{ Raw emissions (kg)/fuel (gal) } & \multicolumn{2}{c|}{ Scaled emissions (kg)/fuel (gal) } & \multicolumn{2}{c|}{ Departure count } \\
\cline { 2 - 10 } & HC & CO & NOx & Fuel & HC & CO & NOx & Fuel & Unscaled & ASPM \\
\hline \hline ATL & 193375 & 2039187 & 363479 & 29129468 & 264528 & 2789510 & 497222 & 39847714 & 358737 & 490735 \\
ORD & 129900 & 1745597 & 274507 & 21971419 & 188652 & 2535112 & 398664 & 31908856 & 313001 & 454568 \\
DFW & 47134 & 829335 & 150830 & 12232769 & 86249 & 1517580 & 276000 & 22384445 & 183836 & 336397 \\
LAX & 74677 & 804811 & 140372 & 10981814 & 147492 & 1589557 & 277244 & 21689837 & 159719 & 315456 \\
DEN & 106555 & 1103306 & 166677 & 13549440 & 154427 & 1598990 & 241560 & 19636819 & 210819 & 305534 \\
IAH & 90296 & 1064689 & 172448 & 13338263 & 141097 & 1663686 & 269468 & 20842412 & 185925 & 290527 \\
CLT & 56282 & 575474 & 92146 & 7240239 & 135058 & 1380943 & 221119 & 17374126 & 100565 & 241322 \\
PHX & 56266 & 807600 & 165489 & 12353982 & 70165 & 1007096 & 206369 & 15405696 & 192035 & 239472 \\
PHL & 65161 & 634558 & 110130 & 8590475 & 197705 & 1925313 & 334146 & 26064371 & 76478 & 232042 \\
DTW & 120886 & 742905 & 132092 & 11714156 & 234521 & 1441251 & 256261 & 22725698 & 117656 & 228255 \\
LAS & 62595 & 817680 & 165936 & 12466008 & 87115 & 1137988 & 230938 & 17349292 & 160323 & 223126 \\
MSP & 86185 & 667450 & 129372 & 10904776 & 159749 & 1237158 & 239799 & 20212643 & 115589 & 214251 \\
JFK & 93699 & 1067920 & 214886 & 16490657 & 200218 & 2281950 & 459172 & 35237525 & 98043 & 209500 \\
EWR & 91208 & 1133733 & 195992 & 15174146 & 138245 & 1718411 & 297067 & 22999614 & 137614 & 208583 \\
LGA & 72348 & 694759 & 130470 & 10615395 & 154187 & 1480662 & 278056 & 22623396 & 89597 & 190948 \\
BOS & 54779 & 581653 & 106174 & 8402538 & 103679 & 1100883 & 200953 & 15903309 & 96561 & 182759 \\
SFO & 50997 & 587693 & 106448 & 8290787 & 88520 & 1020112 & 184771 & 14391064 & 100386 & 174249 \\
IAD & 35077 & 448250 & 77099 & 5997524 & 75000 & 958428 & 164850 & 12823635 & 80113 & 171294 \\
SLC & 53653 & 644433 & 97057 & 7597778 & 76641 & 920546 & 138642 & 10853117 & 119799 & 171128 \\
MCO & 34112 & 449326 & 94046 & 7187196 & 54007 & 711387 & 148897 & 11378993 & 107712 & 170533 \\
\hline
\end{tabular}

Table 4. Scaled and unscaled fuel burn, emissions and departure counts for the top 20 airports (as measured by the ASPM departure count).

departure demand". These metrics are plotted in Figure 3 (using the unscaled data) and in Figure 4 (using the scaled data). Airports for which the departure metric (denoted by the lines with markers) is less than the fuel burn or emissions metric (denoted by the bars) can be considered to have weak emissions/fuel burn performance. We note that these airports are consistent between the unscaled plots (Figure 3 ) and the scaled plots (Figure 4).

We also plot, for each of the top 20 airports, the fraction of the total taxi-out emissions or fuel burn (from the top 20 airports) associated with that airport and the fraction of the top 20 airport departure demand that is associated with it. These plots are shown in Figure 5.

It is also interesting to look at the performance of the airport, not only in terms of the number of departure operations, but also in terms of the number of passengers served. This is reflective of the size of the aircraft being flown at the airport, their seat capacity, etc., ignoring the effects of varying load factors. Figure 6 shows such a plot for the fuel burn performance at the top 20 airports, using the number of departing passengers reported by the Bureau of Transportation Statistics. ${ }^{16}$ We note that the outliers are fairly consistent with those in Figure 5.

\section{Single-engine taxiing}

Fuel burn and emissions can potentially be reduced if all aircraft were to taxi out using only a subset of their engines. This translates to using one engine for twin-engine aircraft, and is therefore referred to as single-engine taxiing. Aircraft engines must be warmed up prior to departure, for a period that ranges from 2-5 min depending on the engine type. Therefore, even if an engine's power is not required for taxiing, it is assumed that all engines must be on for a minimum of five minutes before takeoff. Thus, if the taxi time of an aircraft is less than five minutes, a single-engine taxi-out scenario would not change either the activities of the pilot or the surface emissions of that flight. Conversely, if an aircraft taxies for longer than five minutes, the emissions are reduced by the amount of pollutants that one of its engines would produce for the duration of the taxi time in excess of five minutes (for example, if the taxi time is twelve minutes its emissions will be reduced by the amount of one engine operating for seven minutes).

This procedure is not recommended for uphill slopes or slippery surfaces, or when deicing operations are 

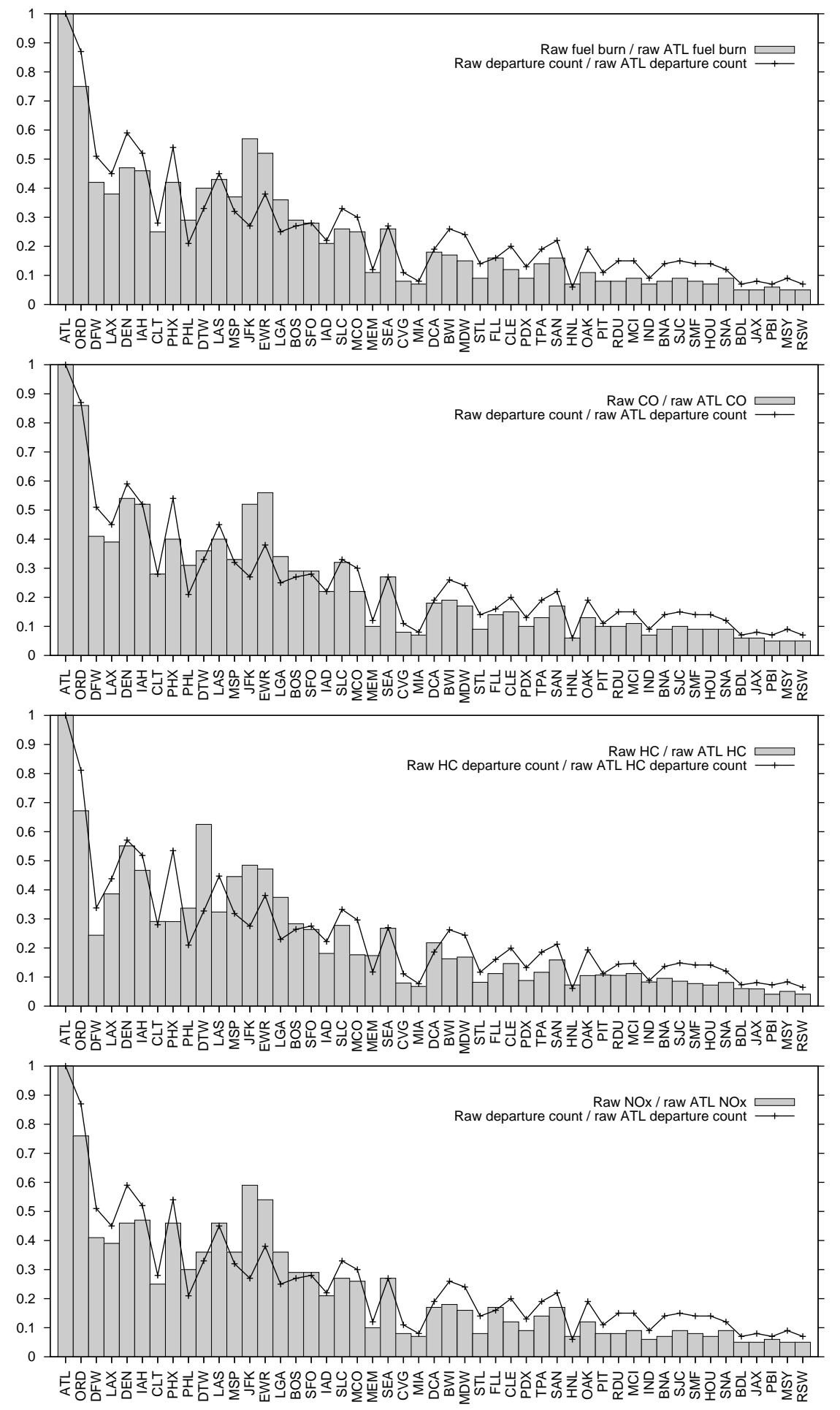

Figure 3. [Bars] Baseline unscaled fuel burn/emissions normalized by the unscaled ATL fuel burn/emissions; [Line] Raw departure count at airport divided by raw departure count at ATL.

required..$^{2}$ Aircraft manufacturers (for example, Airbus) recommend that airlines adopt single-engine taxiing whenever conditions allow it, and yet few airlines have done so. There is a potential for significant savings from single-engine taxiing; for instance, American Airlines is estimated to save $\$ 10-\$ 12$ million a year in this 

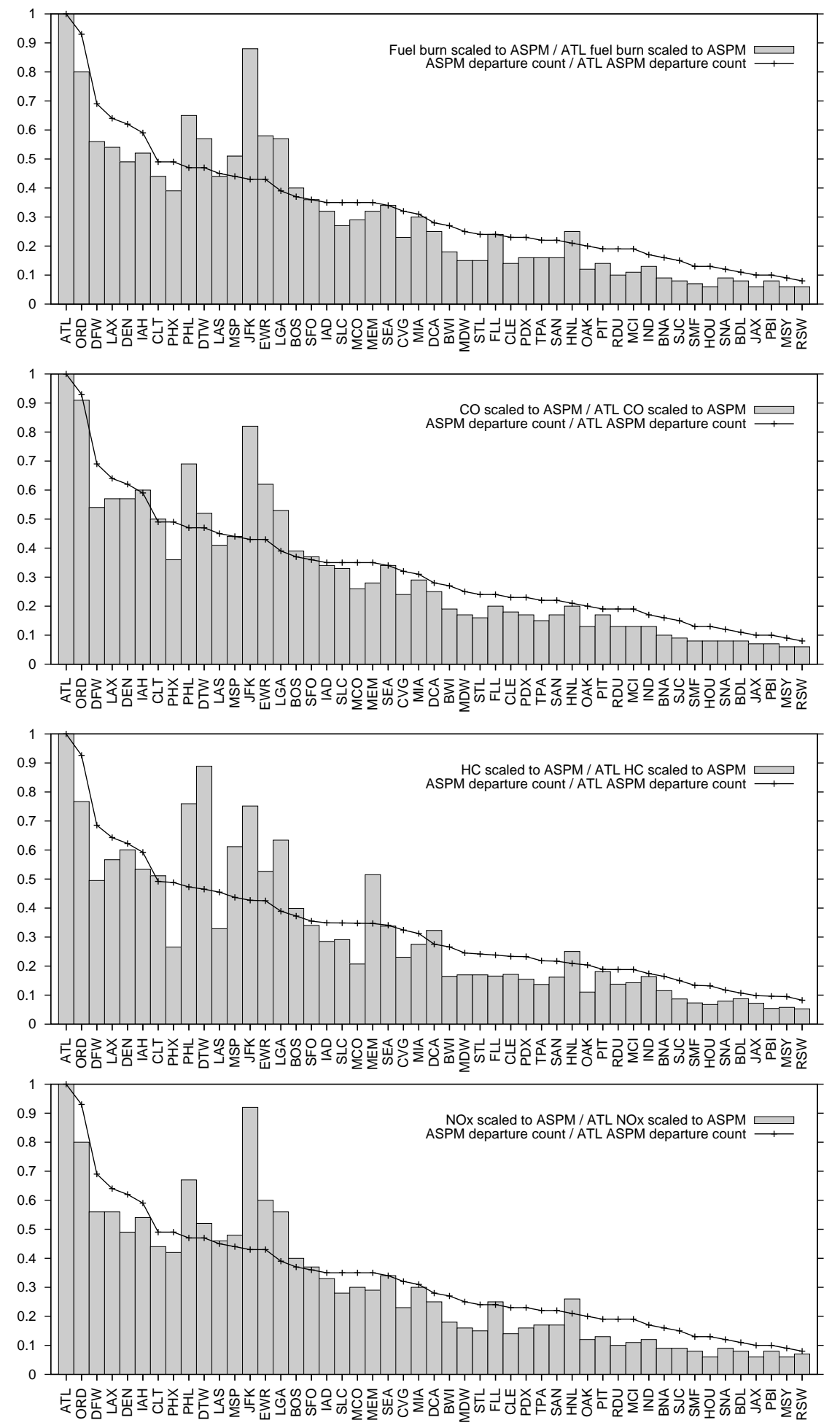

Figure 4. [Bars] Baseline scaled fuel burn/emissions normalized by the scaled ATL fuel burn/emissions; [Lines] ASPM departure count at airport divided by ASPM departure count at ATL.

manner. $^{11}$ 

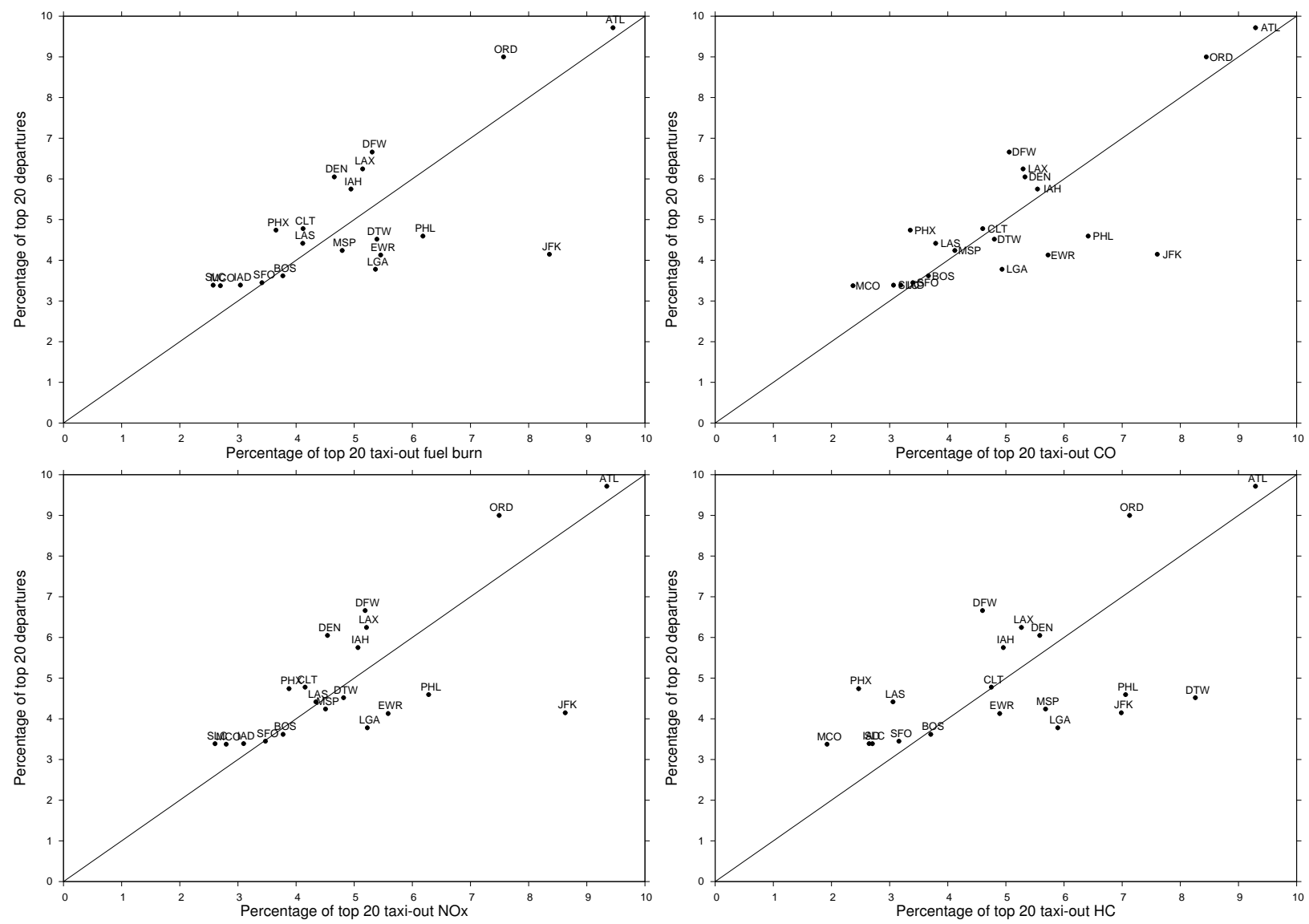

Figure 5. Percentage of top 20 departure demand that each airport accounts for vs. the associated fuel burn (top, left) and emissions as a fraction of total taxi-out fuel burn/emissions from the top 20 airports. The solid line denotes the $45^{\circ}$ line. Points that fall below this line are considered to be weak performers: we note that JFK tends to be a significant outlier in all the plots.

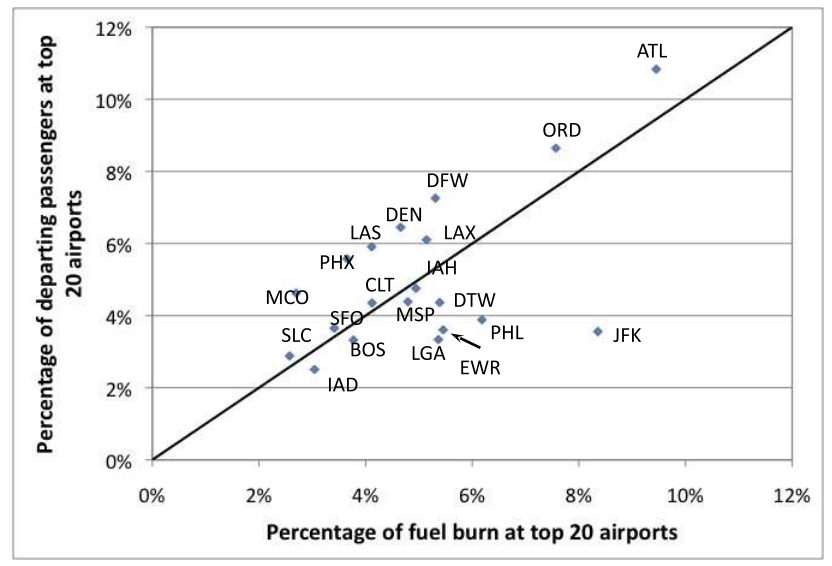

Figure 6. Percentage of top 20 departure passenger demand that each airport accounts for vs. the associated fuel burn as a fraction of total taxi-out fuel burn from the top 20 airports. The solid line denotes the $45^{\circ}$ line. Points that fall below this line are considered to be weak performers: we note that JFK remains a significant outlier.

\section{A. Potential benefits of single-engine taxiing}

We estimate the theoretical benefits of single-engine taxiing at airports in the US. For each of the top 50 airports, and for each departure operation at the airport, we estimate the reduction in fuel burn and different

$$
8 \text { of } 14
$$


emissions were the aircraft to taxi out with one of its engines off. The engine start-up time is assumed to be 5 min for all aircraft.

Using the above information, the single-engine taxi-out fuel burn of flight $i$ in $\mathrm{kg}$, denoted $F B_{i}^{\text {single }}$, is given by

$$
F B_{i}^{\text {single }}=\left(\left[T_{i} \times\left(N_{i}-1\right)\right]+\min \left\{T_{i}, 300\right\}\right) \times F B I_{i},
$$

where $T_{i}$ is the taxi-out time of flight $i$ in seconds, $N_{i}$ is the number of engines on flight $i$ and $F B I_{i}$ is the fuel burn index of each of its engines (in $\mathrm{kg} / \mathrm{sec}$ ).

The single-engine taxi-out emissions from flight $i$ for each pollutant species $j$ (denoted $E_{i j}$, in $\mathrm{kg}$ ) is given by

$$
E_{i j}=\left(\left[T_{i} \times\left(N_{i}-1\right)\right]+\min \left\{T_{i}, 300\right\}\right) \times F B I_{i} \times E I_{i j},
$$

where $E I_{i j}$ is the emissions index for pollutant $j$ from each engine on flight $i$, measured in grams of pollutant per kilogram of fuel consumed. We can sum the above quantities over all departures in the system or in any particular airport in order to obtain the total fuel burn and emissions from single-engine taxiing.

The percentage reductions in fuel burn, $\mathrm{HC}$ and $\mathrm{CO}$ emissions with respect to the baseline scenario are shown in Figure 7. For example, at both JFK and PHL, more than a $40 \%$ decrease in taxi-out fuel burn can theoretically be achieved if all aircraft were to taxi with one engine off (as opposed to taxiing on all engines), with a 5 min start-up time.

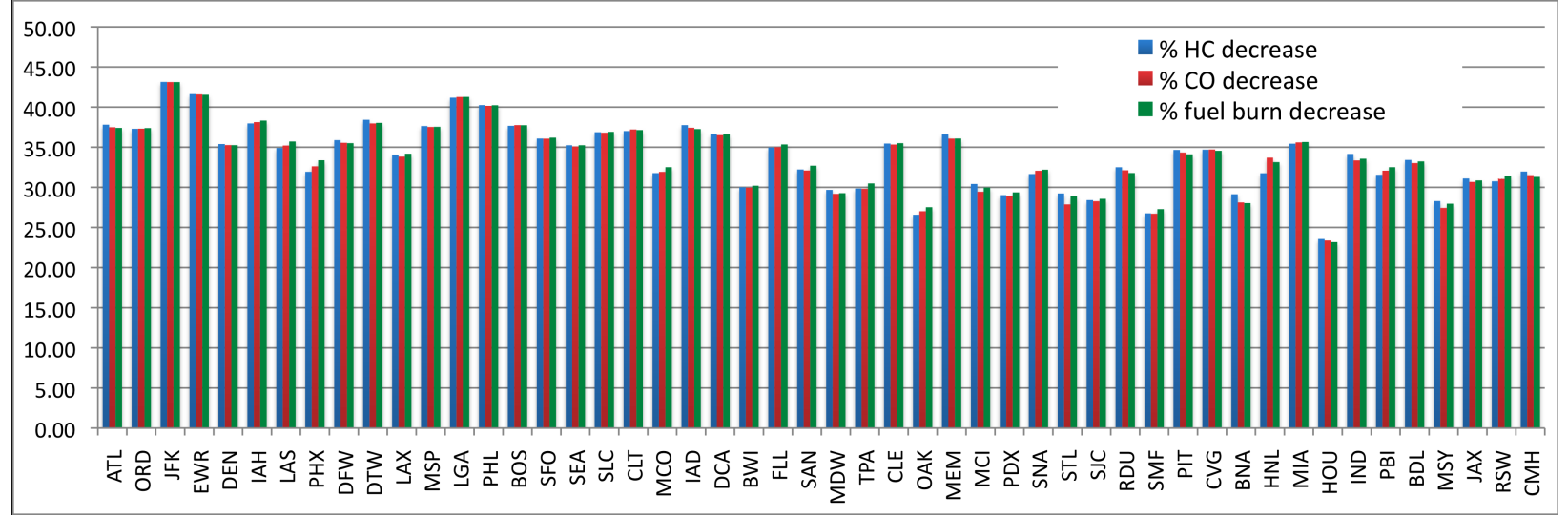

Figure 7. Potential reductions in fuel burn and emissions from single-engine taxiing (compared to baseline emissions) at the top 50 airports in the United States.

\section{B. Operational challenges}

Successful implementation requires improved dissemination of information (for example, knowledge that an aircraft is 5 min from take-off requires information on the status of the departure queue, downstream airspace conditions, and congestion levels on the surface), as well as strategies to increase robustness to unexpected events (such as the detection of mechanical problems during engine start, which would now be closer to the runway, requiring routing of the aircraft back to the gate, as well as assigning it a later departure time). In recent work, the authors present a predictive model of the departure process that allows us to estimate the taxi-out time for a flight, the state of the departure queue, etc. ${ }^{3}$ In addition, during current operations, fire protection from ground staff is not available during engine start if it takes place outside the ramp area. The frequency and impact of such events will have to be evaluated in order to assess the feasibility of single-engine taxiing. It has also been noted that taxiing out on a subset of engines results in reduced redundancy, and increases the risk of loss of braking capability and nose wheel steering. ${ }^{2}$ Some difficulties on tight taxiway turns during single-engine taxiing have been reported by pilots. This appears to be particularly true when there is asymmetry, as in the case of a twin-engine aircraft; it can be difficult to turn in the direction of the engine that is being used. While taxiing on fewer engines, more thrust per engine is required to maneuver, especially on breakaways and 180 degree turns. As a result, care must be taken to avoid excessive jet blast and foreign object damage. For high bypass ratio engines, the warm-up time prior to maximum takeoff 
thrust and the cool-down time after reverse operation have a significant effect on engine life. However, it appears that $5 \mathrm{~min}$ is generally sufficient time for the warm-up process.

\section{Operational tow-outs}

Another approach that has been proposed to reduce surface fuel burn and emissions is that of towing aircraft to the runway, rather than using the engines to taxi. This procedure is alternatively known as dispatch towing. During departure tow-outs, the engines are not turned on until five minutes before takeoff (that is, for warm-up). The power required to tow the aircraft to the runway is generated by tugs. As result, aircraft emissions decrease, but tug emissions are introduced.

\section{A. Potential impact}

Emissions from tugs depend on the fuel that powers the tug as well as the required engine horsepower. We consider three different tug fuel types: diesel, gasoline, and compressed natural gas (CNG). We assume that two different brake horsepower (BHP) settings are required for each engine type; one to tow narrow-body aircraft and one to tow wide-body aircraft. The brake horse power values for each aircraft and tug engine type, and the corresponding fuel consumption, NOx, and CO emission coefficients are shown in Table $5 .{ }^{6}$ The $\mathrm{CO}_{2}$ emission factors are assumed to be $22.23 \mathrm{lb} \mathrm{CO}_{2}$ /gallon of fuel for diesel tugs and $19.37 \mathrm{lb} \mathrm{CO}_{2} /$ gallon of fuel for gasoline tugs, as opposed to $20.89 \mathrm{lb} \mathrm{CO}_{2} /$ gallon of jet fuel burned. ${ }^{7}$

\begin{tabular}{|c|c|c|c|c|c|c|}
\hline \multirow{2}{*}{ Aircraft type } & \multirow{2}{*}{ Tug fuel type } & \multirow{2}{*}{ BHP } & Fuel consumption & \multicolumn{3}{|c|}{ Emissions (g/(BHP-hr) } \\
\cline { 5 - 7 } & & & (gal/BHP-hour) & NOx & CO & HC \\
\hline \hline Narrow body & Diesel & 175 & 0.061 & 11.0 & 4.0 & 1.0 \\
Narrow body & Gasoline & 175 & 0.089 & 4.0 & 240.0 & 4.0 \\
Narrow body & CNG & 175 & $-\mathrm{n} / \mathrm{a}-$ & 6.0 & 120.0 & 2.0 \\
Wide body & Diesel & 500 & 0.053 & 11.0 & 4.0 & 1.0 \\
Wide body & Gasoline & 500 & 0.089 & 4.0 & 240.0 & 4.0 \\
Wide body & CNG & 500 & $-\mathrm{n} / \mathrm{a}-$ & 6.0 & 120.0 & 2.0 \\
\hline
\end{tabular}

Table 5. Tug Brake Horse Power (BHP) specifications and characteristics for different aircraft types. ${ }^{6}$

As in the case of single engine taxiing, we assume that the engine start-up time is $5 \mathrm{~min}$. We also assume that the tugs travel significantly slower than aircraft taxiing on their own engines; we model this by assuming that the taxi time of an aircraft being towed is 2.5 times its value otherwise.

Using the above information, the single-engine taxi-out fuel burn of flight $i$ in $\mathrm{kg}$, denoted $F B_{i}^{\text {tug }}$, is the sum of the fuel consumption in the tug and the fuel burn of the aircraft. The tow-out emissions of pollutant $j$ for flight $i$ using a tug type $k$ are denoted $E_{i j k}^{\text {tug }}$, and are given by

$$
E_{i j k}^{\mathrm{tug}}=\left(T_{i} \times 2.5 \times \mathrm{BHP}_{k i} \times E I_{k j}^{\mathrm{tug}}\right)+\left(300 \times N_{i} \times F B I_{i} \times E I_{i j}\right),
$$

where $T_{i}$ is the taxi-out time of flight $i$ in minutes (and is greater than $5 \mathrm{~min}$ ), $N_{i}$ is the number of engines on flight $i, F B I_{i}$ is the fuel burn index of each of its engines (in $\mathrm{kg} / \mathrm{sec}$ ), $\mathrm{BHP}_{k i}$ is the brake horse power of tug type $k$ to tow flight $i, E I_{i j}$ is the emissions index for pollutant $j$ from each engine on flight $i$, measured in grams of pollutant per kilogram of fuel consumed, and $E I_{k j}^{\text {tug }}$ is the emissions index for pollutant $j$ from a tug of type $k$, measured in grams of pollutant per BHP-sec. We note that these calculations do not include the contribution of the tugs on their return trips to the ramp areas.

\section{B. Operational challenges}

Although it was pursued in the past by Virgin Atlantic for their 747 fleet, tow-outs had to be abandoned after Boeing suggested that the nose landing gear on the 747s were not designed to withstand such loads on

a regular basis. ${ }^{1}$ This concept is currently being revisited by Airbus, which is considering other means of dispatch towing which will not impose the same loads on the nose gear. Our studies have found that before 


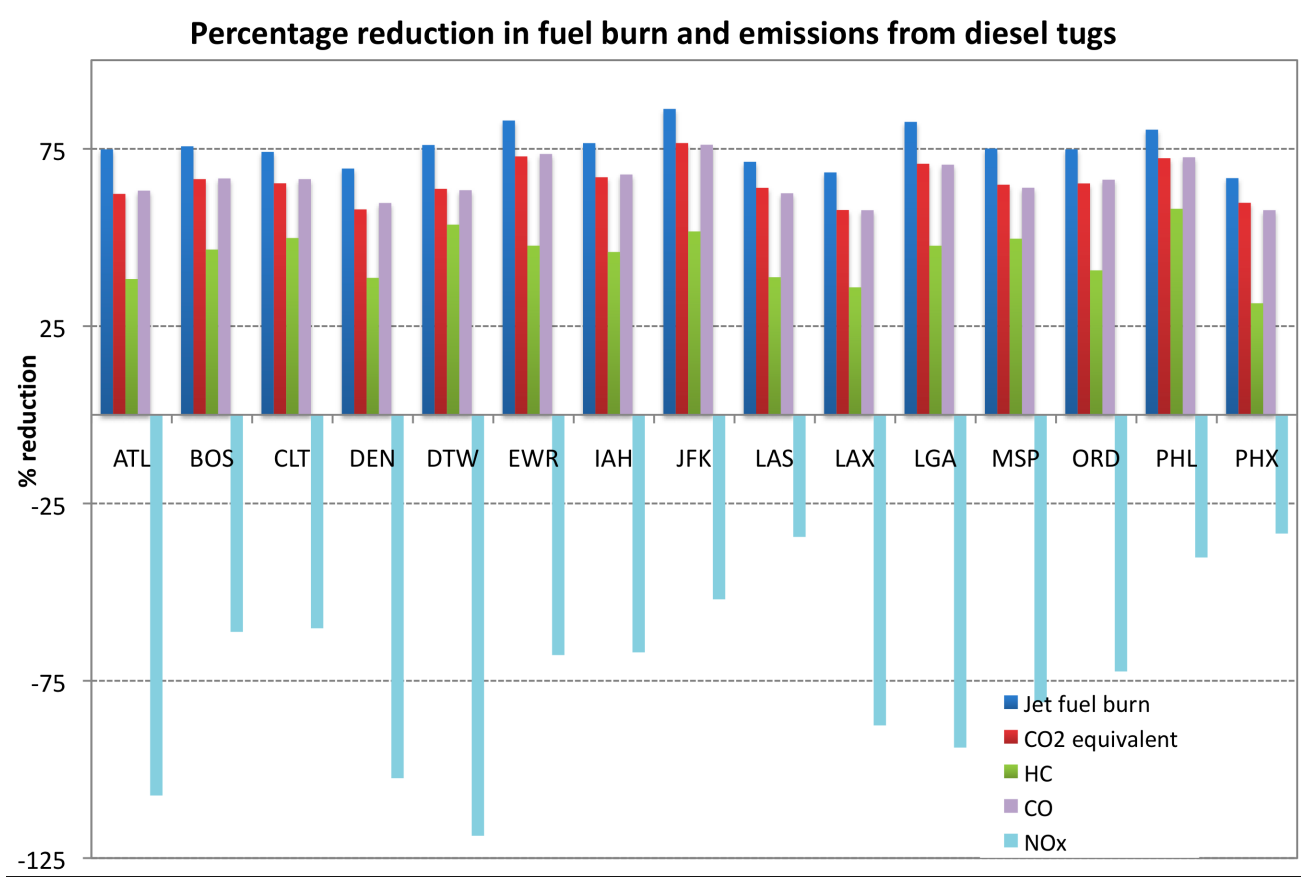

Figure 8. Potential reductions in fuel burn and emissions from operational tow-outs using diesel tugs at the top 15 airports in the United States. Negative values imply an increase in emissions.

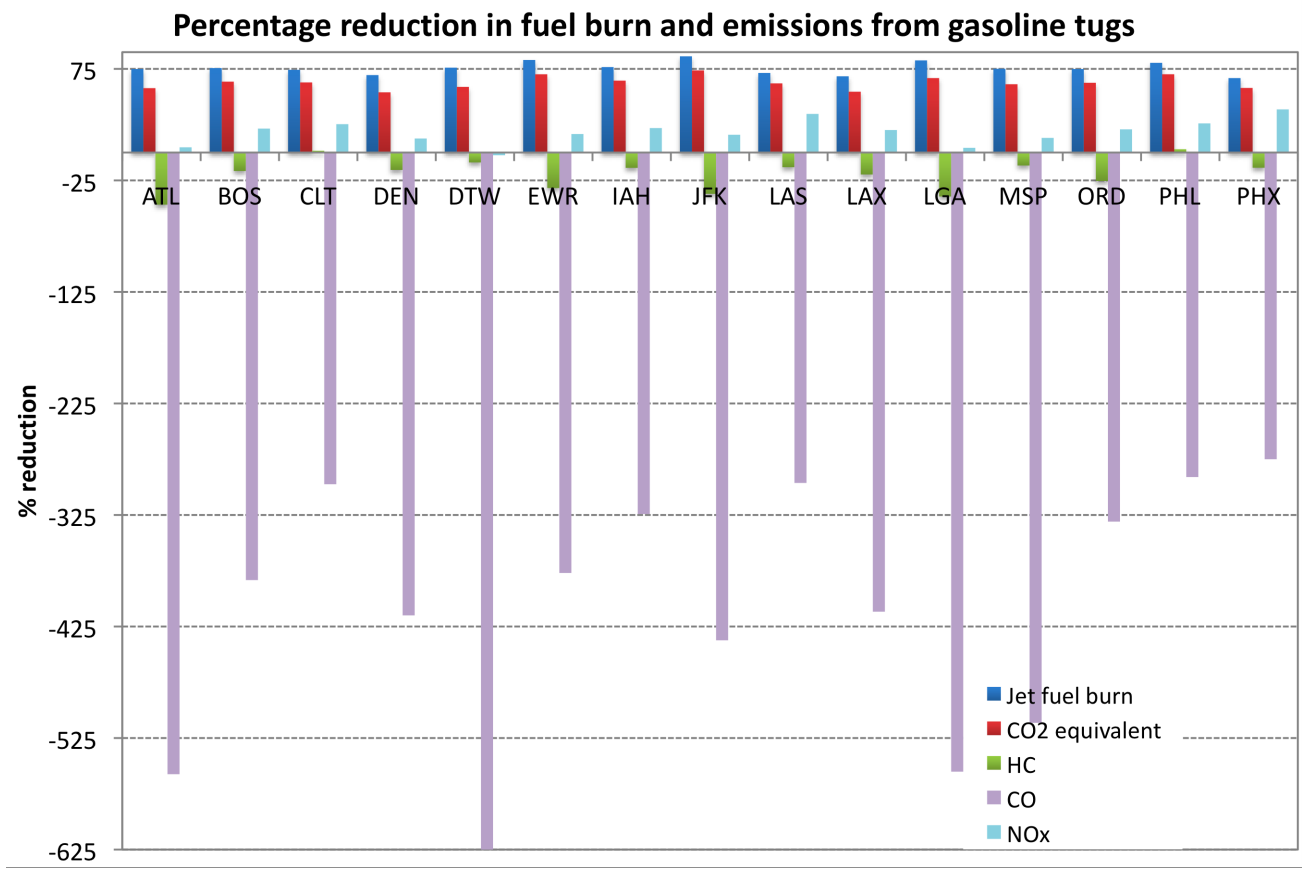

Figure 9. Potential reductions in fuel burn and emissions from operational tow-outs using gasoline tugs at the top 15 airports in the United States. Negative values imply an increase in emissions.

tow-outs are adopted, other factors such as the emissions characteristics of the tugs (for example, diesel tugs will potentially increase NOx emissions), the impact of tow-outs on taxi times and airport throughput (because of reduced speeds: for example, Virgin Atlantic at Heathrow found a 3x increase on the A340-500 


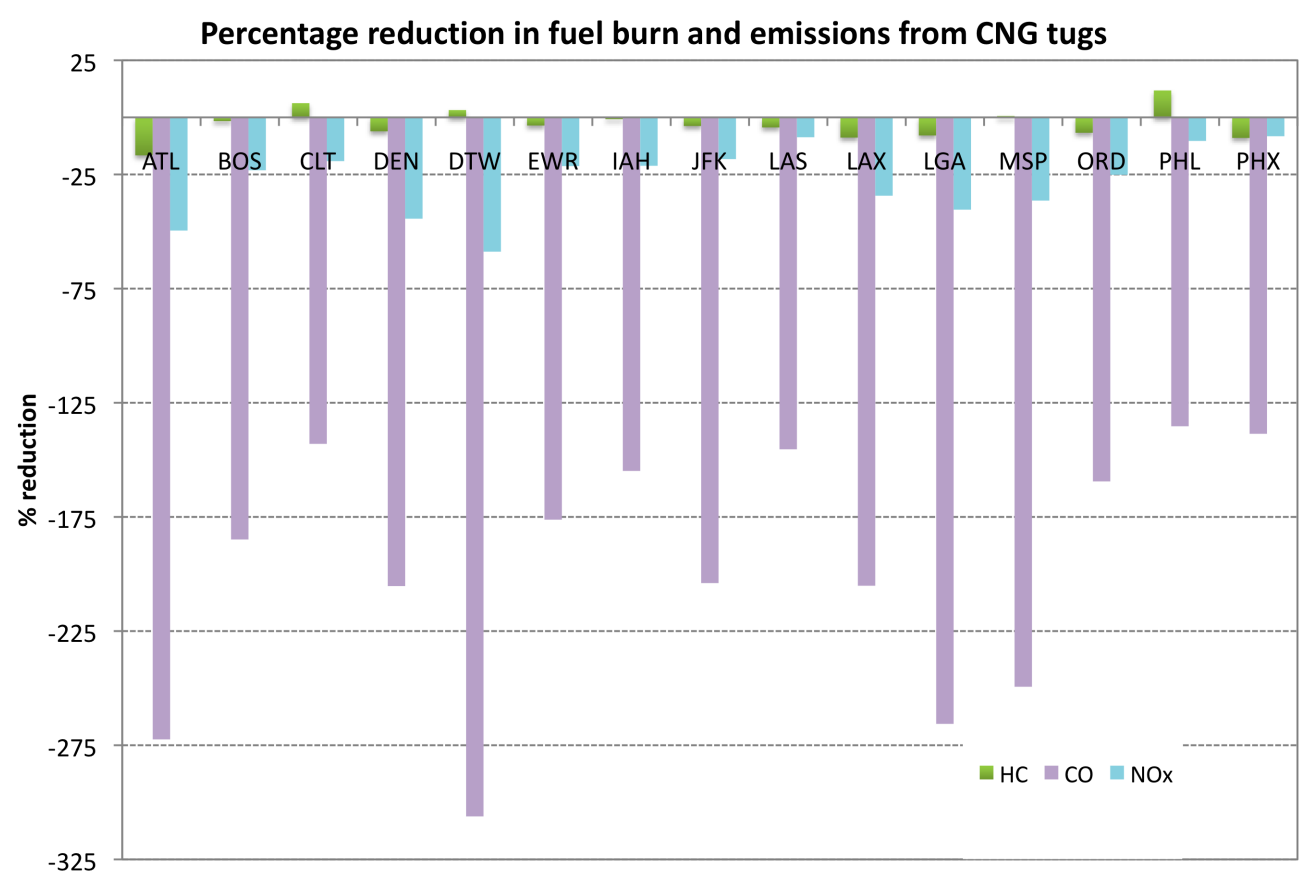

Figure 10. Potential reductions in emissions from operational tow-outs using CNG tugs at the top 15 airports in the United States. Negative values imply an increase in emissions.

taxi time when compared to the normal dispatch procedure), and information requirements (as in the case of single-engine taxiing, a good estimate of the take-off time improves the benefit of tow-outs) will need to be considered. Other operational issues such as communication protocols between the ATC, the cockpit and the tug operator will also have to be evaluated and addressed. If a viable operational towing concept is developed before the proposed field trials, we will also evaluate it in cooperation with the airframe manufacturers. As in the case of single-engine taxiing, tow-outs will require that (all) the engines be started away from the ramp area, with the associated challenges.

\section{Advanced queue management}

Another promising mechanism by which to decrease taxi times, and to thereby decrease fuel burn and emissions, is by limiting the build up of queues and congestion on the airport surface through improved queue management. Under current operations, aircraft spend significantly longer lengths of time taxiing out during congested periods of time than they would otherwise. By improving coordination on the surface, and through information sharing and collaborative planning, aircraft taxi-out procedures can be managed to achieve considerable reductions in fuel burn and emissions.

\section{A. Potential benefits}

We estimate the total "pool of benefits" in fuel burn and emissions reduction that can be achieved by decreasing taxi times. In order to do this, we consider the ideal case, when every departing aircraft taxies for only the length of its unimpeded taxi-out time. This gives us the maximum possible benefit that can be achieved by queue management strategies. For example, at PHL, we have estimated that if every departure taxied out for the unimpeded taxi time (depending on its terminal, season, etc. - approximated by the tenth percentile of ASPM taxi-out times for the given terminal and season), we would achieve a theoretical reduction in taxi-out emissions and fuel burn of nearly $60 \%$. Done naively, this would be equivalent to allowing only one (or very few) aircraft to taxi out at any given time. This would result in a decrease in airport throughput, and an increase in departure delays. We also approximated that at the top twenty 
busiest airports in the US, emissions and fuel reductions could range from $25 \%$ to $60 \%$. Figure 11, which lists the airports in order of relative numbers of ASPM departures, illustrates anticipated reductions in fuel consumption and emissions. We recognize that unimpeded taxi times will be very difficult to achieve at airports; however, we believe that improved queue management when implemented effectively, has the potential to decrease taxi-out delays in addition to emissions and fuel burn.

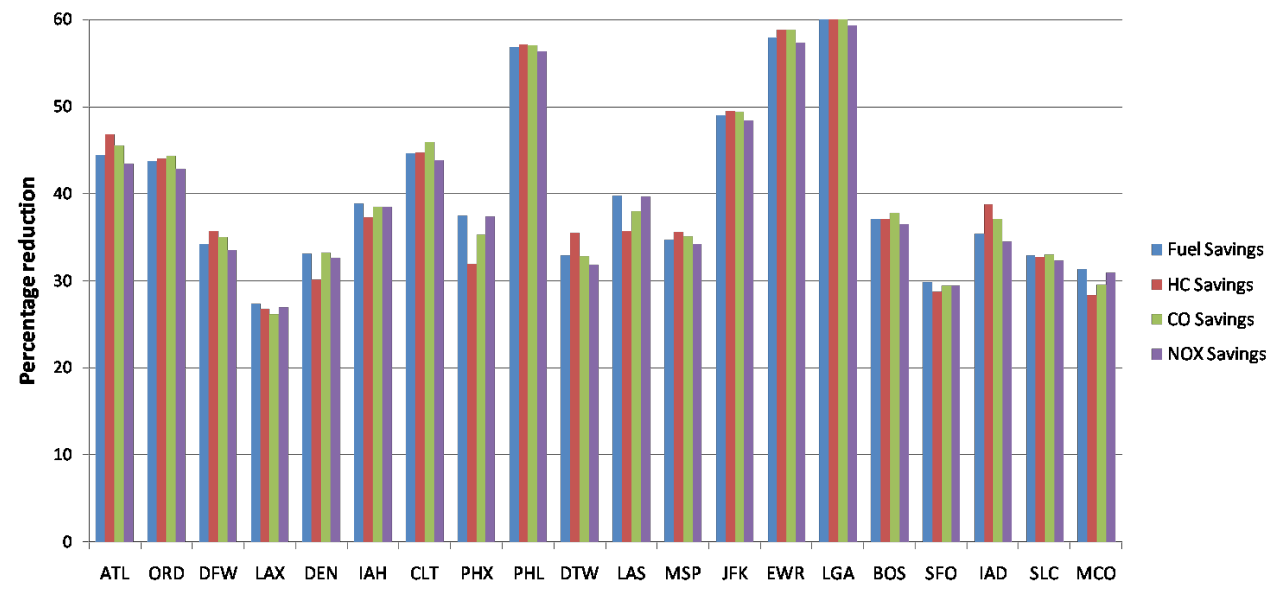

Figure 11. Potential for reductions in fuel burn and emissions through achieving unimpeded taxi times at airports.

\section{B. Operational challenges}

Queue management strategies require a greater level of coordination among traffic on the surface that is currently employed. For example, if gate-hold strategies are to be used to limit surface congestion, there need to be mechanisms that can manage pushback and departure queues depending on the congestion levels. In addition, ATC procedures need to also be addressed: for example, currently, departure queues are FirstCome-First-Serve (FCFS), creating incentives for aircraft to pushback as early as possible. If gate-hold strategies are to be applied, virtual queues of pushback priority will have to be maintained. We note that airline on-time performance metrics are calculated by comparing the scheduled and actual pushback times; this again creates incentives for pilots to pushback as soon as they are ready rather than to hold at the gate to absorb delay. In addition, gate assignments also create constraints on gate-hold strategies; for example, an aircraft may have to pushback from its gate if there is an arriving aircraft that is assigned to the same gate. This phenomenon is a result of the manner in which gate use, lease and ownership agreements are conducted in the US; in most European airports, gate assignments appear to be centralized and do not impose the same kind of constraints on gate-hold strategies.

In recent work, we have focused on modeling the taxi-out process as a queuing network. ${ }^{3}$ The rationale for applying this modeling approach is the fact that the queues which are formed in the system during the taxiing process offer suitable control points, and proper modeling of the queues enables the application of strategies to control them. Ideally, one would like to maintain the surface queues as close as possible to the smallest loads which will keep the airport throughput at its capacity limit. This approach will decrease taxi-out times without sacrificing the throughput of the airport.

\section{Conclusion}

This paper presented the results of research aimed at evaluating promising opportunities for surface optimization to reduce surface emissions at airports. It presented estimates of current fuel burn and emissions impacts of airport taxi-out processes, evaluated the potential benefits of proposed strategies to reduce them, and identified some of the critical implementation barriers that need to be overcome prior to the adoption of these approaches at airports. Ultimately, an intelligent combination of these strategies will have to 
be adopted in order to reduce fuel burn and emissions at airports, without compromising the efficiency of operations. This might comprise of adopting queue management strategies during the most congested periods of operation, using operational tow-outs during periods of low demand when the reduced speeds will not adversely impact system throughput, and employing single-engine taxiing during intermediate times. The next steps in this research include refinement of the emissions inventories using experimental data, integration with local air quality models, and an assessment of the emissions impacts of proposed surface operations management strategies.

\section{References}

\footnotetext{
${ }^{1}$ Virgins green idea loses its pulling power, March 2008. http://www.timesonline.co.uk/tol/news/environment/article3516551.ece.

${ }^{2}$ Airbus Flight Operations Support and Line Assistance. Getting to grips with fuel economy. Issue 3, July 2004.

${ }^{3}$ H. Balakrishnan, I. Deonandan, and I.Simaiakis. Opportunities for reducing surface emissions through airport surface movement optimization. Technical report, Massachusetts Institute of Technology, 2008. Technical report Number ICAT-2008-7.

${ }^{4}$ Bucher and Company. JP Airline Fleets International (2006/2007), 2006.

${ }^{5}$ Christophe Cros and Carsten Frings. Alternative taxiing means - engines stopped. Presented at the Airbus workshop on "Alternative taxiing means - Engines stopped", November 2008.

${ }^{6}$ Energy and Environmental Analysis, Inc. Technical data to support FAA's advisory circular on reducing emissions from commercial aviation, September 1995.

${ }^{7}$ Environmental Protection Agency. Unit conversions, emissions factors, and other reference data, November 2004.

${ }^{8}$ Federal Aviation Administration. Airline Service Quality Performance, accessed September 2008. http://aspm.faa.gov/ASQP.

${ }^{9}$ Federal Aviation Administration. Aviation System Performance Metrics, accessed September 2008. http://aspm.faa.gov.

${ }^{10}$ E. R. Feron, R. J. Hansman, A. R. Odoni, R. B. Cots, B. Delcaire, W. D. Hall, H. R. Idris, A. Muharremoglu, and N. Pujet. The Departure Planner: A conceptual discussion. Technical report, Massachusetts Institute of Technology, 1997.

${ }^{11}$ John Heimlich. Coping with sky-high jet fuel prices, March 2008.

${ }^{12}$ S. C. Herndon, T. Rogers, E. J. Dunlea, R. C. Miake-Lye, and B. Knighton. Hydrocarbon emissions from in-use commercial aircraft during airport operations. Environmental Science and Technology, 2006.

${ }^{13}$ S. C. Herndon, J. H. Shorter, M. S. Zahniser, D. D. J. Nelson, J. T. Jayne, R. C. Brown, R. C. Miake-Lye, I. A. Waitz, P. Silva, T. Lanni, K. L. Demerjian, and C. E. Kolb. $\mathrm{NO}$ and $\mathrm{NO}_{2}$ Emissions Ratios Measured from in use Commercial Aircraft during Taxi and Take-Off. Environmental Science and Technology, 2004.

${ }^{14}$ Scott C. Herndon, Ezra C. Wood, Megan J. Northway, Richard Miake-Lye, Lee Thornhill, Andreas Beyersdorf, Bruce E. Anderson, Renee Dowlin, Willard Dodds, and W. Berk Knighton. Aircraft Hydrocarbon Emissions at Oakland International Airport. Preprint, November 2008.

${ }^{15}$ International Civil Aviation Organization. ICAO Engine Emissions Databank, July 2007.

${ }^{16}$ U.S. Department of Transportation. Bureau of Transportation Statistics, accessed Sept. 2008. www.transtats.bts.gov.
} 